\title{
Water vapor sorption dynamics in different compressions of eelgrass insulation
}

\author{
Kirstine Meyer Frandsen ${ }^{1, *}$, Yovko Ivanov Antonov ${ }^{1}$, Per Møldrup ${ }^{1}$ and Rasmus Lund Jensen ${ }^{1}$ \\ ${ }^{1}$ Department of the Built Environment, Aalborg University, 9220 Aalborg, Denmark
}

\begin{abstract}
Eelgrass shows potential in meeting the rising demands towards new, sustainable materials. It hosts a range of characteristics that benefits its application as a building material, such as thermal and acoustic insulating properties that can compete with conventional mineral wool insulation. However, as a porous bio-based building material, the moisture performance of eelgrass must be assessed to ensure its practical application. In this study, experimental investigations are conducted by a new automated vapor sorption analyzer (VSA) to measure adsorption and desorption of water vapor on different compressions of eelgrass insulation, ranging from loose strands to densely compacted insulation batts. Overall, higher sorption dynamics are observed in eelgrass insulation compared to conventional mineral wool insulation. Loose strands of eelgrass depict higher dynamics (including hysteresis) for the full range of relative humidity in comparison to insulation batts, potentially due to additional binder. Increasing the compression of eelgrass insulation batts results in lower sorption dynamics in the $>70 \%$ relative humidity range. A Guggenheim-Anderson-deBoer model is applied that shows good fit with the experimental data and may be applied in moisture transfer calculations. This study furthers the potential of compressing eelgrass for application in passive design strategies through its moisture buffering capabilities.
\end{abstract}

\section{Introduction}

Rising requirements towards sustainability are increasing the demand for alternative building materials. Bio-based materials show large potential as they address issues relating to environmental impact and energy savings [1]. However, the hygrothermal characteristics of these porous bio-based building materials exhibit larger dynamics in comparison to conventional building materials [1]. Hygroscopic building materials show potential in reducing energy consumption and improving the indoor environment through their moisture buffering capacity [2-4]. An understanding of a material's hygrothermal performance is therefore essential to ensuring optimal application in a building.

Eelgrass is a bio-based material that has traditionally been used on Læsø in Denmark for thatched roofing [5]. More modern methods of application have been introduced over recent years, for example in the development of the Modern Seaweed House on Læsø $[5,6]$ and introduction in material catalogues on building innovation projects. As a building material, eelgrass carries many beneficial properties in being non-toxic and recyclable with long durability, high fire-resistance and low susceptibility to mold [7] due to its presence of natural minerals. Importantly, it holds thermal and acoustic insulating abilities that can compete with conventional mineral wool insulation [8].

In its active state, eelgrass acts as natural coastline protection [9]. It then washes up on coastlines, from where it will rot or be removed from beaches at a large expense for Danish municipalities [7]. However, if the eelgrass is gathered and processed into a building material, it binds the $\mathrm{CO}_{2}$ rather than releasing it to the atmosphere during decomposition. After collection, the eelgrass is cleaned, crushed and dried. From here, it is used as thermal insulation in its loose form or produced into insulation batts in a shredding, cafting and pressing process that allows for different compressions, depending on the intended application.

As a porous bio-based building material, the moisture performance of eelgrass should be assessed. Current hygrothermal characterization of eelgrass insulation is mostly limited to requirements set by industry standards. Existing investigations have included LCA-analysis [7], test programs based on CE marking [8], and Cradle to Cradle Gold certification [10], but very little information is presented on the sorption phenomena in the material. Sorption dynamics is an essential element to transient calculations of moisture transfer [11] as it depicts the ability of a material to store moisture.

In this paper, water vapor sorption isotherms of different compressions of eelgrass insulation and mineral wool insulation are studied. The sorption isotherms are experimentally derived using a new fully-automated Vapor Sorption Analyzer (VSA) that allows for accurate, high-resolution adsorption-desorption isotherms to be measured in a short time-span. This method has previously been applied on bio-based building materials [12] and in the soil research field [13,14]. Based on the derived isotherms, the Guggenheim-Anderson-deBoer (GAB) model is applied to examine the relation between increased compressions of eelgrass insulation and

Corresponding author: kmf@build.aau.dk 
hygrothermal properties. Overall this study aims to aid in performance predictions so that optimal and appropriate design of eelgrass insulation may be ensured in future.

\section{Materials and methods}

\subsection{Fibrous insulation materials}

Three different compressions of eelgrass insulation were investigated in this study. These include loose eelgrass (EEG-L) and two compressions of insulation batts with respective densities of $70 \mathrm{~kg} / \mathrm{m}^{3}$ and $125 \mathrm{~kg} / \mathrm{m}^{3}$ (EEG-70 and EEG-125). EEG-L was obtained from a thatched roof on Læsø, whereas EEG-70 and EEG-125 were produced by Læsø Zostera. This study also included mineral wool insulation (Rockwool A-batts: RW) to provide a comparison to a conventional building material. Table 1 depicts the properties, details and images of the investigated materials. All eelgrass materials have been cleaned and dried. However, the insulation batts are produced using additional binder (polyethylene and polypropylene fibers) that is not present in the loose eelgrass, enabling a comparison from the original state (loose eelgrass) to processed product (insulation batts).

All of the materials are applicable as thermal insulators. Table 1 shows that EEG-70 performs as well as RW in terms of thermal conductivity at $37 \mathrm{~mW} / \mathrm{m} \cdot \mathrm{K}$, where-as EEG-L performs slightly less at $45 \mathrm{~mW} / \mathrm{m} \cdot \mathrm{K}$. The thermal conductivity of EEG-125 is unknown but may be presumed to be similar. The bulk density of EEG-L is the required density when using loose eelgrass as specified by the European Technical Approval [15].

\subsection{SEM imaging}

Scanning Electron Microscopy (SEM) was used as a visualization technique for initial qualitative observation of the material structure. The SEM images were acquired at two respective levels of magnification: low (100x) and

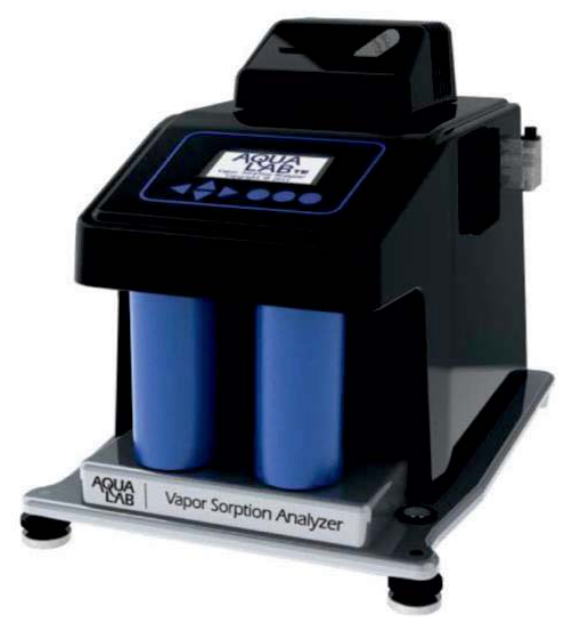

Fig. 1. Aqualab Vapor Sorption Analyzer (VSA) used to achieve high-resolution water vapor sorption isotherms [16].

high (5000x). A single sample of each material was examined.

\subsection{Water vapor adsorption-desorption isotherms}

Water vapor sorption isotherm were measured by the Aqualab VSA seen in Figure 1. The Dynamic Dew-point Isotherm (DDI) method was applied, which has previously been validated in [12-14], where it has shown agreeable isotherms when compared to the Dynamic Vapor Sorption (DVS) method and the current standard DS/EN ISO 12571 [17]. The DDI method employs the chilled-mirror dewpoint technique to automatically dry and wet the sample placed inside the VSA chamber. The sample mass is measured simultaneously by a highprecision magnetic balance.

Adsorption-desorption isotherms were measured on samples of approximately $1-2 \mathrm{~cm}^{3}$. No pressure is applied on the samples during the measurements.

Table 1. Origin and properties of the investigated fibrous insulation materials: three eelgrass and one mineral wool.

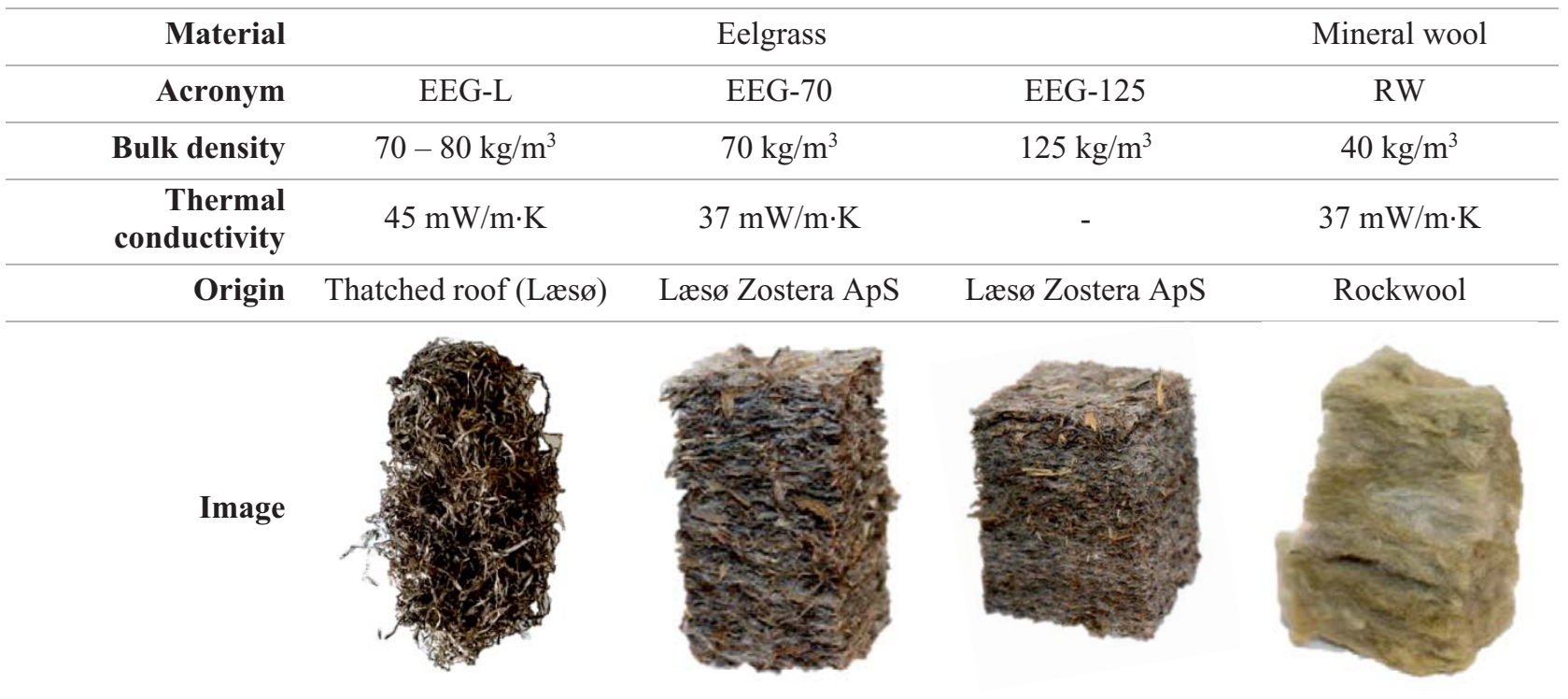


Low magnification
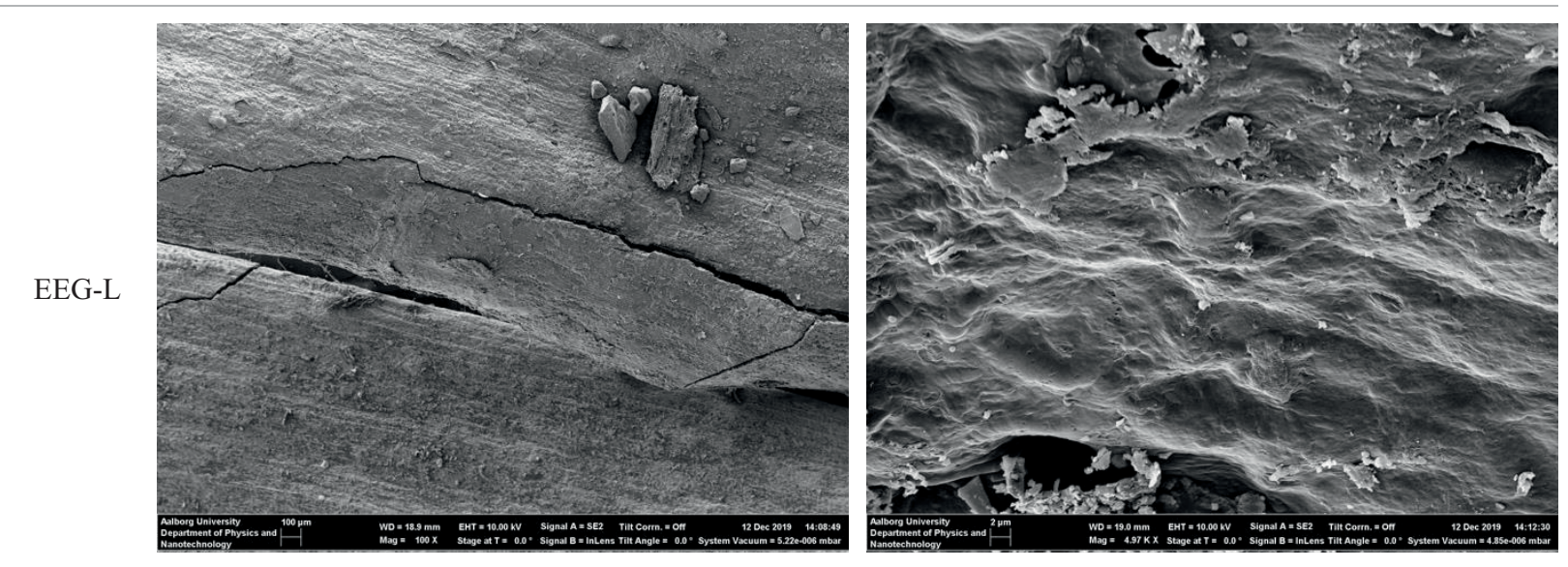

EEG-70
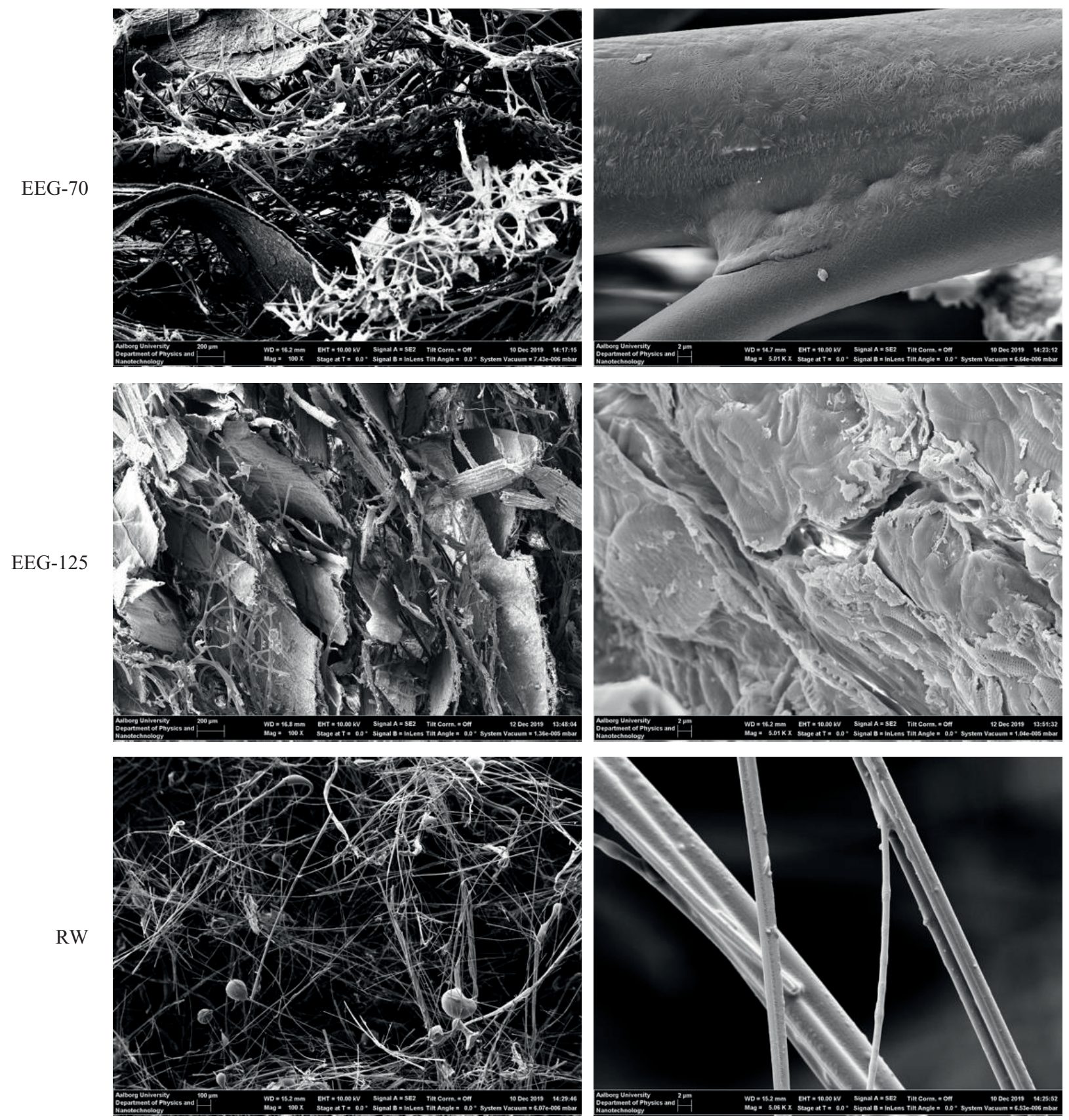

Fig. 2. SEM images of the four fibrous insulation materials. Images were created at low (100x) and high (5000x) magnification. The scale can be found at the bottom of each image. 
(a)

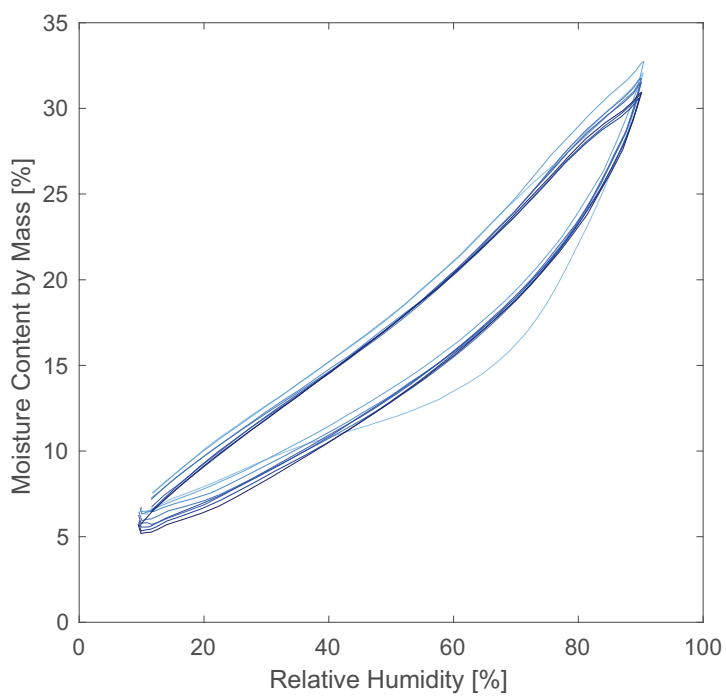

(c)

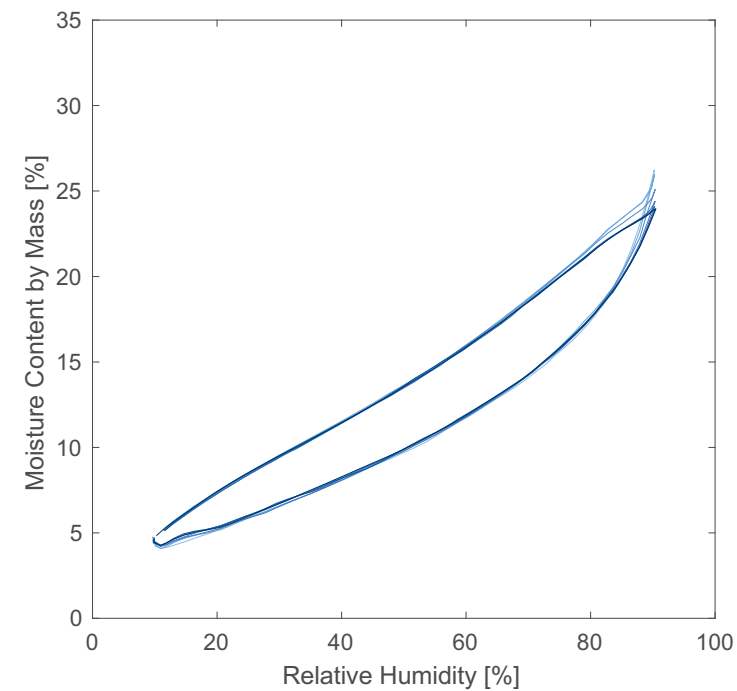

(b)

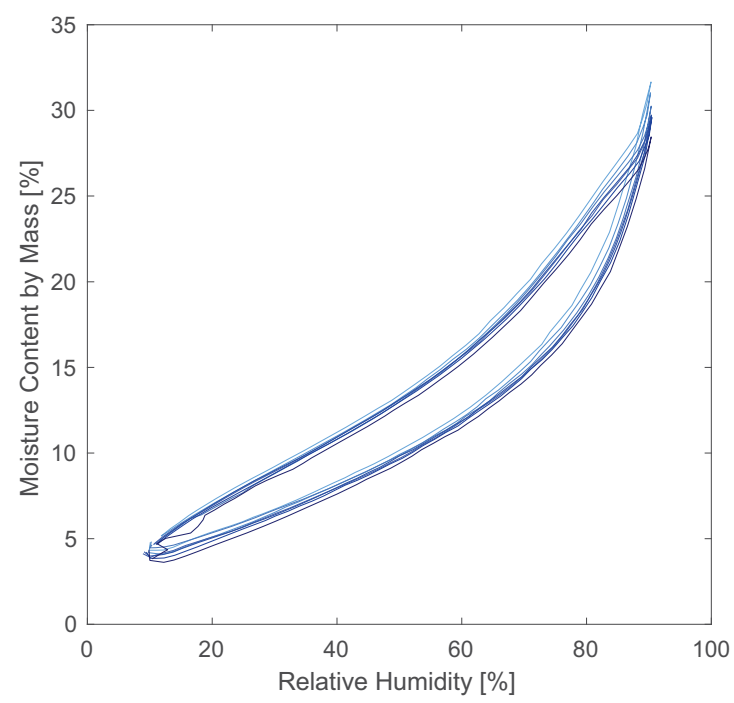

(d)

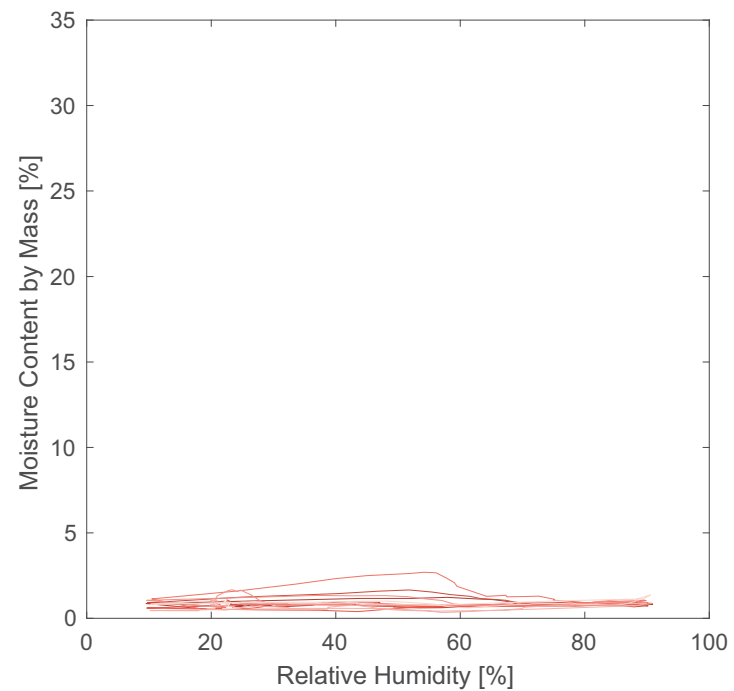

Fig. 3. Water vapor sorption isotherms for the four insulation materials (a) EEG-L (b) EEG-70 (c) EEG-125 (d) RW. Each figure shows eight consecutively measured isotherms; the isotherms are shaded darker with each consecutive cycle.

The hygroscopic test range was set as the relative humidity (RH) from $10 \%$ to $90 \%$ with a resolution of $2 \% \mathrm{RH}$ at a temperature of $23^{\circ} \mathrm{C}$. Only one sample of each material was investigated. A single isotherm was produced in approximately 24 hours. Due to the short time-requirements of the VSA, eight consecutive isotherms were measured for each sample.

The Guggenheim-Anderson-deBoer (GAB) model was subsequently applied to the derived isotherms to analyze the impact of compressions on GAB coefficients and provide a mathematical model for future moisture transport calculations.

\section{Results and discussion}

\subsection{SEM images}

Resultant SEM images for each of the investigated materials can be seen in Figure 2. An initial comparison of the eelgrass insulation samples shows a difference in the sizes of the eelgrass fibers from the strands of loose eelgrass to the denser insulation batts. The eelgrass strands have clearly been shredded in the production of insulation batts.

The insulation batts depict a more chaotic structure consisting of fibers from both the eelgrass and binder. This can be observed in the images of the materials shown in Table 1, where it is also evident that EEG-125 has been compressed to a more dense material. Bio-based building materials with low density commonly exhibit low thermal conductivity [1]. As mentioned, EEG-70 has a comparable thermal conductivity to RW; with the increased density, it may be presumed that EEG-125 has a thermal conductivity that exceeds $37 \mathrm{~mW} / \mathrm{m} \cdot \mathrm{K}$.

Observation of the high magnification images show the rough surface of all three eelgrass materials, including hairs on the fiber of EEG-70 and cell structures in EEG-125. The dents on the surface of EEG-L show the impact from micro-organisms that have previously lived on the material. The combination of all SEM images indicate a broad pore-size distribution for eelgrass insulation, which is commonly known to increase the potential for hysteresis due to complex connectivity between different pore scales [18]. 
RW consists of smooth fibers in contrast to the eelgrass insulation. Clusters of melted fibers are apparent in the images, due to high heat during production. The fibers of the mineral wool appear significantly thinner at approximately $2-10 \mu \mathrm{m}$ in diameter as opposed to $\sim 200 \mu \mathrm{m}$ in EEG-70 and with less variation in its pore structure.

\subsection{Water vapor sorption isotherms}

The derived adsorption-desorption isotherms for each material are presented in Figure 3. Moisture content is given in $\%(\mathrm{~kg} / \mathrm{kg}$ dry weight of the material). From the isotherms it is evident that the bio-based eelgrass insulation presents significantly higher sorption dynamics than those present in mineral wool insulation. In fact, RW depicts little-to-no moisture dynamics, which is expected, as it is commonly advertised as a hydrophobic material.

The shredding of the eelgrass materials and addition of binder has a clear impact on sorption properties. EEG-L shows an overall higher sorption isotherm in the full range of $10 \%$ to $90 \%$ RH when compared with EEG-70 and EEG-125. This could potentially be due to the addition of binder used to form insulation batts. However, all three eelgrass insulations depict a similar isotherm type (shape).

Furthermore, there is an impact from the increased compression of eelgrass insulation batts (EEG-70 to EEG$125)$. In the hygroscopic range from $10 \% \mathrm{RH}$ up to $70 \% \mathrm{RH}$ the materials exhibit similar sorption dynamics. However, in the high hygroscopic range $(>70 \% \mathrm{RH})$ the materials start to exhibit different behavior. Peak moisture content levels are higher for the lower density eelgrass insulation; this is evident in the peak moisture content at $90 \% \mathrm{RH}$ of $28.5 \%$ and $24.0 \%$ for EEG-70 and EEG-125 respectively.

Hysteretic behaviour appears to decrease from EEG-L to EEG-70 and EEG-125. This is validated in Table 2, where the local hysteresis index $H_{s, 50 \%}$ is calculated as the difference in moisture content between the adsorption and desorption curve at $50 \% \mathrm{RH}$, as specified in [19]. As previously mentioned, this may be due to a broad poresize distribution. EEG-70 and EEG-125 exhibit similar sorption dynamics, including hysteresis, further highlighting the similarities also visualized by the SEM images.

Table 2. Local hysteresis index at 50\% RH for each respective eelgrass insulation material.

\begin{tabular}{cccc}
\hline & EEG-L & EEG-70 & EEG-125 \\
\hline$H_{s, 50 \%}$ & $4.7 \%$ & $3.6 \%$ & $3.8 \%$ \\
\hline
\end{tabular}

Previous literature studies have observed similar shapes and magnitudes in isotherms in other bio-based materials, such as hemp and flax shives and fibers [20], hempcrete [21] and Jack pine and palm wood [22]. These suggest that the high sorption dynamics present in biobased materials may be attributed to the open material structures such as those also present in eelgrass.

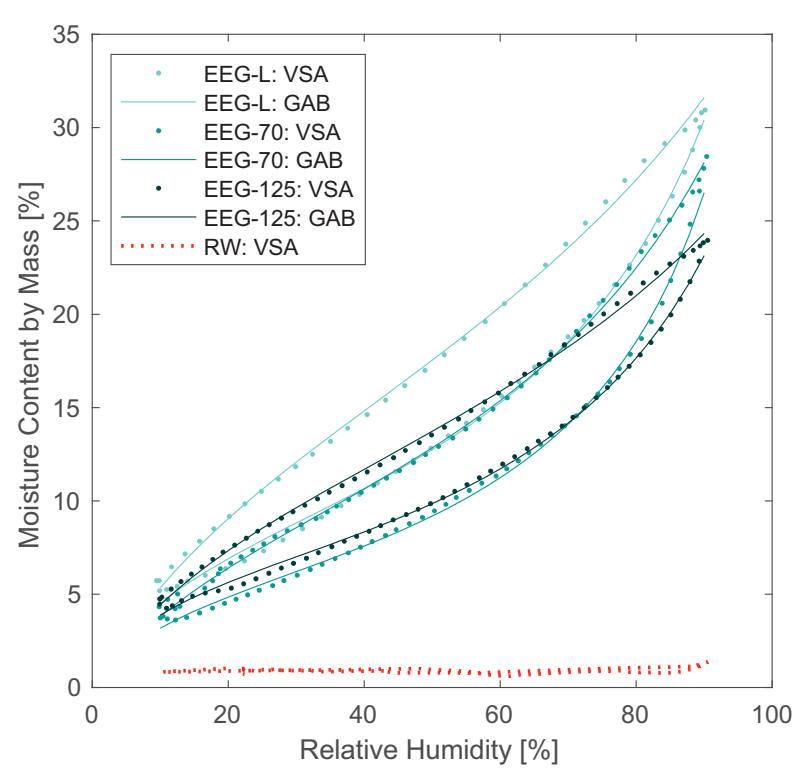

Fig. 4. Experimental sorption data with correlated GAB model. VSA denotes the experimental data; GAB denotes the mathematical model. The GAB model is not applied to the RW isotherm.

Finally, it may be noted that the repetitions of 8 cyclic sorption isotherms show no significant differences per repetition.

\subsubsection{Mathematical model}

The Guggenheim-Anderson-de Boer (GAB) model is commonly applied as an approach to correlating material moisture content to RH as an extension of Langmuir's model. It is expressed as follows:

$$
m=\frac{W_{m} K C a_{w}}{\left(1-K a_{w}\right)\left(1-K a_{w}+K C a_{w}\right)}
$$

Where $m$ is the moisture content of the material on a dry basis [kg moisture/kg dry weight], $a_{w}$ denotes the water activity (\% RH), and $W_{m}, C$ and $K$ are constants.

$W_{m}$ is a constant that expresses the monolayer capacity. $C$ and $K$ are both adsorption constants that relate the energies of interaction between the initial and later sorbed molecules [23].

Table 3. GAB coefficients $W_{m}, C$ and $K$ for modeling the three eelgrass insulation materials.

\begin{tabular}{llllll}
\hline Isotherm & & $\boldsymbol{W}_{\boldsymbol{m}}$ & $\boldsymbol{K}$ & $\boldsymbol{C}$ & $\mathbf{R}^{\mathbf{2}}$ \\
\hline \multirow{2}{*}{ EEG-L } & Ads & 8.71 & 0.804 & 10.4 & 0.997 \\
& Des & 16.6 & 0.594 & 6.89 & 0.998 \\
\hline \multirow{2}{*}{ EEG-70 } & Ads & 5.82 & 0.876 & 10.4 & 0.997 \\
\cline { 2 - 6 } & Des & 10.2 & 0.737 & 6.65 & 0.999 \\
\multirow{2}{*}{ EEG-125 } & Ads & 6.51 & 0.807 & 13.8 & 0.998 \\
\cline { 2 - 6 } & Des & 12.5 & 0.596 & 7.88 & 0.998 \\
\hline
\end{tabular}

The mathematical model is applied to the final respective adsorption and desorption isotherms (cycle no. 8) for EEG-L, EEG-70 and EEG-125. It is not applicable to the RW isotherm, as it is not sigmoidal. The software Moisture Analysis Toolkit is used to derive the GAB coefficients listed in Table 3. The fitted model is 
plotted in Figure 4, along with the experimental VSA data points. The data points illustrate the high resolution attainable by the VSA. As the figure indicates, there is a good fit between the mathematical GAB model and the experimental data, with the biggest discrepancy occurring around the peak water activity $(90 \% \mathrm{RH})$, which is also the upper limit for application of the GAB model [23].

Observation of the GAB coefficients show that the constant $W_{m}$ differs from loose eelgrass to insulation batts. The coefficient is significantly larger for EEG-L than EEG-70 and EEG-125, which corresponds to the dynamics during monolayer adsorption, occurring in the low hygroscopic range. This is in agreement with the observed isotherms, where EEG-L showed higher overall moisture dynamics.

Interestingly, the coefficient $C$ is very similar between EEG-L and EEG-70, whereas there is an increase for EEG-125. This effect may be observed on peak moisture content levels around $80 \%$ to $90 \% \mathrm{RH}$ on the fitted model in Figure 4. Both EEG-L and EEG-70 experience a sharp increase in moisture content in contrast to the EEG-125, suggesting that more dense insulation batts decreases moisture dynamics in a high $\mathrm{RH}$ environment.

If additional densities of insulation batts are investigated and show agreement with the existing data, there is potential for the development of a model linking the coefficients to eelgrass insulation density. This can be applied as an estimation of water vapor sorption isotherms for may be used for the design of eelgrass insulation batts.

\section{Conclusion}

Eelgrass insulation shows high sorption dynamics that are commonly observed in bio-based building materials. These dynamics are significantly larger for all three insulation structures than for conventional mineral wool insulation, that has almost non-existent sorption dynamics, typical for a hydrophobic material. These hygroscopic characteristics give eelgrass potential for application in passive building design strategies through its moisture buffering capacity.

When processed from loose eelgrass into insulation batts, eelgrass changes in structure and consequentially sorption dynamics. This was observed by both SEM imagery and water vapor sorption isotherms. Loose eelgrass presented higher moisture dynamics in the whole hygroscopic range $(10 \%$ to $90 \% \mathrm{RH})$ prior to the shredding and addition of binder. This was also observed in the decrease of hysteresis from EEG-L to EEG-70 and EEG-125. Minor variations were present between the two insulation batts.

The increased compression of insulation batts largely impacted the sorption dynamics in the range of $70 \% \mathrm{RH}$ and above, which approaches the upper threshold for relative humidity levels common in the indoor environment. In this range, the low-density insulation (EEG-70) showed higher sorption properties than the high-density insulation (EEG-125). However, both the SEM imagery and sorption isotherms showed little other variation.
The GAB model was applied and showed good agreement with the experimental data, proving it a valid model to be applied in calculations of moisture transfer. This proves an effective tool to determine the appropriate design of building elements for optimal indoor comfort, material durability and energy consumption. The correlations that were observed linking the density of eelgrass insulation batts to the GAB coefficients could be investigated further on additional eelgrass insulation densities.

Further investigations are recommended to include pore-size distribution, surface tension and surface diffusion to fully link the pore structure effect to sorption dynamics and deepen the understanding of hygrothermal performance and moisture buffering capacity of eelgrass insulation.

This project is funded by the Independent Research Fund Denmark grant no. 8022-00032B "Non-Equilibrium Water Vapor Sorption in Building Materials [NOWA]". We express our gratitude to Leonid Gurevich for his help in performing SEM imaging and to Læsø Zostera for providing us with eelgrass insulation samples.

\section{References}

1. S. Amziane, F. Collet, State-of-the-Art Report of the RILEM Technical Committee 236-BBM: Bioaggregates Based Building Materials (2017) doi:10.1007/978-94-024-1031-0.

2. O.F. Osanyintola, C.J. Simonson, Moisture buffering capacity of hygroscopic building materials: Experimental facilities and energy impact, Energy and Buildings. (2006) doi:10.1016/j.enbuild.2006.03.026.

3. H. Wan, Z. Sun, G. Huang, X. Xu, J. Yu, Calculation of the maximum moisture buffering thickness of building wall layer of hygroscopic material, Building and Environment. 160 (2019) 106173. doi:10.1016/j.buildenv.2019.106173.

4. M. Zhang, M. Qin, C. Rode, Z. Chen, Moisture buffering phenomenon and its impact on building energy consumption, Applied Thermal Engineering. 124, 337-345 (2017) doi:10.1016/j.applthermaleng.2017.05.173.

5. S. Nielsen, A. Klebak, Realdania, Tanghuse på Lasø - Det Moderne Tanghus, 2013. https://realdania.dk/projekter/tanghuse-paalaesoe---det-moderne-tanghus.

6. B. Widera, Possible Application of Seaweed as Building Material in the Modern Seaweed House on Læsø, in: 30th International PLEA 2014 Conference (2014) doi:10.13140/RG.2.1.1638.2881.

7. B.E. Pallesen, Bceredygtige Tangisoleringsmåtter fra ålegraes, Ministry of Environment and Food Denmark, (2018) https://www2.mst.dk/Udgiv/publikationer/2018/ 06/978-87-93710-35-1.pdf. 
8. S. Technology, D. Centre, Production and Properties of Insulation Mats Made from Sea Grass 2 Production of Sea Grass Insulation Mats 3 Results from Tests Carried out at the Danish Building Research Institute, Internation Conference on Energy, Environment, Ecosystems and Sustainable Development, 626-631 (2007)

9. J.R. Rasmussen, J. Havenhand, P. Grønkjær, Alegraes og klimaforandringer (2013) doi:Report 2013:45, ISSN: 1403-168x.

10. Cradle to Cradle Product Innovations Institute, Cradle to Cradle Certified ${ }^{T M}$ Gold: Seaweed Insulation (2018)

https://cdn.c2ccertified.org/Certifications/Conver t_A_S/Seaweed_Insulation/Conve_Seawe_Gold _CERT3852_2018-12-17.pdf.

11. C. Rode, Combined heat and moisture transfer in building constructions, Kgs. Lyngby, Denmark, (1990)

12. Y.I. Antonov, K.M. Frandsen, P. Møldrup, E. Arthur, L. Wollesen de Jonge, M. Pomianowski, R.L. Jensen, Linking Three Methods for Quantifying Water Vapor Sorption Dynamics in Bio-Based Building Materials (2020)

13. E. Arthur, M. Tuller, P. Moldrup, L.W. de Jonge, Rapid and fully automated measurement of water vapor sorption isotherms: new opportunities for vadose zone research., Vadose Zone Journal. 13, 185 (2014)

14. E. Arthur, M. Tuller, P. Moldrup, L. Wollesen de Jonge, Evaluation of a Fully Automated Analyzer for Rapid Measurement of Water Vapor Sorption Isotherms for Applications in Soil Science, Soil Sci Soc Am J. 78, 754-760 (2014) doi:10.2136/sssaj2013.11.0481n.

15. Deutsches Institut für Bautechnik, European Technical Approval: ETA-05/0008 (2010).
16. D.I. Devices, Vapor Sorption Analyzer Operator's Manual (2016)

17. CEN, DS/EN ISO 12571:2013 Hygrothermal performance of building materials and products Determination of hygroscopic properties (2013)

18. J. Carmeliet, F. Descamps, G. Houvenaghel, $A$ multiscale network model for simulating moisture transfer properties of porous media, Transport in Porous Media (1999) doi:10.1023/A:1006500716417.

19. E. Arthur, M. Tuller, P. Moldrup, L.W. de Jonge, Clay content and mineralogy, organic carbon and cation exchange capacity affect water vapour sorption hysteresis of soil, European Journal of Soil Science. (2020) doi:10.1111/ejss.12853.

20. Y. Jiang, M. Lawrence, A. Hussain, M. Ansell, P. Walker, Comparative moisture and heat sorption properties of fibre and shiv derived from hemp and flax, Cellulose. 26, 823-843 (2019). doi:10.1007/s10570-018-2145-0.

21. F. Collet, J. Chamoin, S. Pretot, C. Lanos, Comparison of the hygric behaviour of three hemp concretes, Energy and Buildings. (2013) doi:10.1016/j.enbuild.2013.03.010.

22. S. Ouertani, S. Azzouz, L. Hassini, A. Koubaa, A. Belghith, Moisture sorption isotherms and thermodynamic properties of Jack pine and palm wood: Comparative study, Industrial Crops and Products. 56, 200-210 (2014) doi:10.1016/j.indcrop.2014.03.004.

23. R.D.P. Andrade, L.M. Roberto, C.E.C. Pérez, Models of sorption isotherms for food: Uses and limitations $\mid$ Modelos de isotermas de sorcion para alimentos: Usos y limitaciones, Vitae. 18, 325334 (2011). 